\title{
Approaches to the values and anti-values meaning description
}

\author{
Violette Ilyina ${ }^{1 *}$ \\ ${ }^{1}$ Russian New University, 105005, Radio str. 22, Moscow, Russian Federation
}

\begin{abstract}
Chronopsycholinguistics approach to the values and anti-values study allows us to describe the values components meaning in a certain historical period and its influence on the language consciousness images perception and interpretation in different cultures. The consciousness is studied at 3 levels (the public consciousness official level, the intermediate level of social consciousness, the common consciousness level).
\end{abstract}

\section{Introduction}

The chronopsycholinguistic approach is a basic one for showing the values meaning development in a certain era or a certain period of historical time. The values form a consciousness value framework at three levels [7]. We mean the public consciousness official level which is examined by analyzing the value (anti-value) meaning semantic components, represented in encyclopedic sources; the public consciousness intermediate level which is considered by studying the value meaning semantic components pointed in lexicographic sources, as well as in the Russian paremiological resource. The definite culture representatives consciousness is outlined with the help of associative fields studying results. They were obtained during the psychosemantic experiment, which was represented as values (anti-values) semantic fields and dendrograms. The purpose of the study is to define the chronopsycholinguistic approach to the time analysis of the values ethnic meaning on the different levels of the language consciousness as actual.

\section{Objects and Methods}

\subsection{Chronopsycholinguistic approach to the study of values}

The content of values and anti-values is not stable, time (historical epoch) makes its own adjustments. The question arises about the prospects of describing values and anti-values using time as a tool for analyzing their content. Such a possible approach to describing the evolution of the content of values can be a chronopsycholinguistic approach, which is based on the idea of time in general, as well as on the psychological and speech time in particular. Time as a philosophical category is analyzed by Husserl (phenomenology), Heidegger

* Corresponding author: violette-viola@inbox.ru 
(existentialism), Bergson (intuitionism), and Dilthey (philosophy of life). If we speak about time as a psychological category, we determine it as a system of the person's life events temporary relations reflection in the consciousness. Chronopsychology (used after A.V. Petrovsky) explores the socio-psychological foundations of the person's time experience. The physiological conception of D. G. Elkin's time perception [5] demonstrates that the time perceptions are localized in the brain. The author also points out their physiological mechanisms, the various analyzers' role and their second-signal connections. The individual time flow speed is studied by B. I. Tsukanov [4]. A. A. Yershov [2] suggests to investigate the mental time correlation with physical time, and also classifies the types of time, indicating the existence of abstract, metric, relativistic, biological one. Time as a sociological category defines, directs and structures the attitude of a collective or group to time. It is a field of scientific interest to T. A. Nestik [9]. In linguistics, there are various areas of time research, including the historical direction of the study of temporality (atomic studies of temporality (vocabulary, individual word classes, syntactic structures) in a separate historical cross-section of a language or several languages). Special attention should be paid to the structural direction [8], where time is considered as a syntactic category. In this case we deal with the syntactic time of a sentence as an object of the analysis. Also, a separate direction is the psychosystematic direction, which is based on Guillaume's idea of operational time. Fiction time is also an object of particular interest, since it exists in quasi-reality. It is a complex multi-dimensional structure that can accelerate and slow down its course, stop, go in the opposite direction, interrupt, contract and stretch. It is through the study of fiction time that we can trace the evolution of a person's attitude to time (observation-experience-an attempt to ignore it). In linguistics the duration can be defined as a part of the broader conception of time represented in the language. We definitely mean the aspectuality, the temporal localization, the taxis, and the temporality. Duration is a special language category and is closely connected with the field of aspectuality. It is possible because the duration is inherent component of the verb's grammar meaning that is existed in the human mind (action - process - duration) [10]. We also insist on distinguishing between internal and external action duration. The internal one can be defined with the aspectuality as the verb category. The external one can be defined with the predicate context (linguistic and extra linguistic). The duration is closely connected with the temporality, which is, as A.V. Bondarko believes, combined with the aspectuality. These two categories are based on the relation between the action and time [1].

\subsection{Language time and speech time}

Having briefly outlined the existing concepts of time in various sciences, we turn directly to the concept of language time as the basis for further analysis of speech time. In this connection we believe necessary objective and subjective time to be treated as the consciousness categories that can be found in language and speech. The objective time can be described in the language with the help of lexical category and grammatical tense. Temporal vocabulary has lexical time meaning. The grammatical category of time includes the morphological category of verb tense, as well as syntactic time. In the Russian language the core of the temporality semantic field consists of verbs of the present, past, and future tenses of perfect and imperfect types (time can be defined by a relation of an event to the moment of speech). In other words, the functional-semantic category of temporality is the basis for distinguishing 2 groups of words: 1) group of words of time meaning implicit expression (emotions, emotional words, words expressing evaluation, basic values and antivalues), 2) group of words of time meaning explicit expression (grammatical meaning of verb tense, temporal vocabulary). Words can express time implicitly because the time 
meaning is a component of their semantics. Words can express time explicitly because some words have the category of lexical time meaning and the category of grammatical tense. We propose to distinguish one more group of words that have time meaning in the speech situation [11], it means that words acquire this meaning in a narrower and broader linguistic environment.

Some facts become evident. Firstly, there is a definite tie between time and consciousness as time is an attribute of matter and an innate image (because a child is able to recognizes time in the prenatal period). This connection is realized in the language with the help of lexical and grammatical categories based on the speech situation temporal reference to the moment of speech. We have come closer to understanding language time. To get closer to understanding subjective (psychological) time reflection in speech we apply to time definition existing in psycholinguistics. Time can be interpreted as a personal psychological category of the language consciousness. Time can also be interpreted as a meaningful linguistic category in the language which is possible to be analyzed in the speech of native speakers. Time is a language consciousness individual image expressed in speech. Time is the duration assessment of speech production and perception process. As a result we point at the definitions' weak point that is precisely their choice of a definite characteristic as the basic one. It means that we have no possibility to investigate of the psychological time realisation aspect in the speech process in general. It is vital for our time study to describe precisely the time category as duration. Psychological time is responsible for a particular life experience perception duration and realizes with the help of explicit and implicit ways of time meaning expression in a person's speech [3].

In this regard, we believe it is logical to focus on the psycholinguistic aspects of the problem of studying time in the framework of chronopsycholinguistics (author's term). Our subject is psychological (subjective) time that we distinguish as duration in the language consciousness of a nationally and culturally determined person and our object is speech time. We suggest defining speech time as the psychological time verbalization process in the person's speech. It means that this is the personal subjective perception and assessment of the life events period realized in the speech. It could be done with the help of two types of words. Firstly, we mean words with the lexical and grammatical meaning of time. Secondly, we specify words with an explicit and implicit emotional and evaluative element in their semantic structure. We suggest describing speech time as consisting of three basic elements. We propose the lexical part (the lexical meaning of time), the grammatical part (morphological and syntactic meaning of time), the contextual component (meaning of time in the speech situation). We pay attention to the presence of two components of language time in the structure of speech time, which is due to the fact that language time is a part of speech time. We propose to distinguish two types of time. If we give the definition to the language time we mean an innate image of consciousness. The speech time should be described as the consciousness image that is nationally and culturally defined [3].

\subsection{Methods}

The usage of interpretive and comparative methods during our objects investigation let us employ complex approaches (hypothetic and deductive methods), statistical data processing, analogy and generalization, being the leading ones. We also use the associative experiment, the semantic differential method, and the component analysis method. During associative experiment ("directed" associative experiment) the individual is asked to name only words of a certain grammatical or semantic class. This method is used in psycholinguistics to form semantic fields based on analyzing the consciousness concepts. 


\section{Results}

The intermediate level of social consciousness let us describe the ordinary level of social consciousness. It can be depicted with the help of the value content semantic members represented in a dictionary entry given in different lexicographic resources. We are revealing the anti-value war meaning. To fulfil this task, we are going to describe its contents semantic members, represented in lexicographic sources: "armed struggle between States", "struggle to achieve their goals", "manifestation of hostility to something", "quarrels", "fighting", "capture", "entity", "hostile relationships", "cruelty", "horror", "changes", "violation of rights", "getting profit".

We analyze the semantic components of the anti-value war content based on the analysis of the texts of 19 centuries presented in the national corpus of the Russian language, namely "confrontation", "duration", "armed struggle between States", "struggle for achieving one's goals", "manifestation of hostility to something", "fighting", "quarrels (interpersonal conflict)".

We also draw our attention to the identified semantic components of the content of the anti-value war based on the analysis of texts of the 18th century presented in the national corpus of the Russian language, namely "service", "data", "armed struggle between States", "struggle for achieving one's goals", "manifestation of hostility to something", "fighting". Thus, all identified semantic components are subdivided into two classes. The first group will consist of matching semes that were identified on the base of the texts' analysis dated eighteenth, nineteenth and twentieth centuries ("armed struggle between States", "struggle to achieve their goals", "manifestation of hostility to something", "fighting"). The second group is formed by semes, whose meanings coincide on the base of the analysis of texts of the 20th century and the 18th century ("entity"), as well as on the base of texts of the 20th century and the 19th century ("quarrels"). The third group is formed by semes that were specific to the Russian culture carriers naive worldview in the 18th century ("service"), in the 19th century ("confrontation", "duration"), in the 20th century ("hostile relations", "cruelty", "horror", "changes", "violation of rights", "getting profit", "capture").

The intermediate level of public consciousness is described by analyzing the proverbs content semantic components of the anti-value war represented in the Russian paremiological fund:

- patriotism (people who do not want to fight and are not inclined to aggression, in a state of extreme necessity, will stand up for their homeland, their home and family. At the same time, the struggle for a just cause will double their strength and they will be much stronger in spirit than those who are fighting just for an idea): we do not want to fight, but we will not give up our land; he who fights for his own is given double strength;

- suffering (war itself is very cruel. In a stressful situation of military operations, old people can mobilize themselves and fight shoulder to shoulder with the young, and sometimes the threshold of pain and suffering is so exceeded that even a boy looks like an adult man): war is a harsh test: some are young, others are old;

- pain (war leaves its mark on every person. Those who were in the war return with scars or cripples. Those who were in the rear and provided the front, grow old before their time and their faces are covered with wrinkles. In war, blood is shed and death is common): war marks everyone: a scar - to the military, a wrinkle - to the civilian; war loves blood; war does not know mercy, it steps over corpses; war does not heal, but cripples;

- victory (it is hard to fight, and victory is a reward for suffering. In the war and after it, it becomes obvious who is worthy of glory, and who is a disgrace for several generations of descendants): the war will not write off anything, it will only write off: some glory, others - shame; war is difficult, but victory is red; 
- evil (war is worse than any even the most terrible disease, because war is evil. When we hear about the horrors of war, we try to imagine them, but what we hear is not comparable to how hard it is to be an eyewitness): war is worse than the plague; war is evil, and peace is good; it is easy to listen to war, but it is hard to see;

- looting (in addition to the usual heroic pages, there are also morally and morally difficult pages that describe looting (looting of civilians, embezzlement of property of the dead) and looters to whom war is a way of profit): to whom war, to whom it is mother;

- bravery (even bullets fly around the brave, to put it another way, bravery is worthy of sincere respect and honor): who is not afraid of death, the bullet avoids;

- warlords (there is a different attitude in the popular consciousness about warlords. On the one hand, these are people who are trying to profit from the war. On the other hand, these are the people who raised the regiments to attack and were the first to expose their chests to bullets): people quarrel, and voivodes feed; in war, the army is strong if there is a strong voivode [6].

Thus folk wisdom is passed down from generation to generation, and therefore is not affected by time. Proverbs are a traditional basic part of the culture of any nation. If we have to characterize this process in terms of time, we can call it as a non-discrete process. On the one hand, we are describing changes in the content of values influenced by different historical times, on the other hand, we highlight the unchangeable components of the nation cultural heritage.

\section{Conclusion}

It is the chronopsycholinguistic approach that allows us to analyze the dynamics of the values development. It is also helpful in forming the value framework of language consciousness in a certain period of historical time and in describing the influence of time on the language consciousness images perception and interpretation by native speakers of different cultures. For example, the analysis of the content of texts dating the 20th century shows that Russian people experience frustrating emotions when they think about war, but the war represented in the texts of the 19th century is perceived as a long-term confrontation, and in the texts of the 18th century as an inevitable phenomenon of reality. Such observations were made during the preliminary experiment but still the obtained results indicate their significance for the future study of psychological time in language consciousness. We have described the content of universal values on the example of the anti-value war. We were aimed to study the values and anti-values ethnic content in the Russian native speakers language consciousness. This process implied our description of the official level of public consciousness content, the content of the intermediate level of public consciousness, the ordinary level of public consciousness. The current cross-section of ideas about war among native speakers of Russian language consciousness showed that the semantic components that make up the core ("aggression", "enslavement") moved to the periphery, and the peripheral semantic components ("rudeness", "debauchery") moved closer to the core of the semantic field. The data obtained indicates the instability of the content of values and antivalues due to time, that is, we draw our special attention to the evolution of the values content over successive epochs. Further study of this problem becomes possible precisely within the framework of chronopsycholinguistics, a branch of psycholinguistics that implements a new stance to the time problem expression and investigation in the field of psycholinguistics. By mentioning it we underline the possibility of time interpretation as duration, its existence in the consciousness and its reflection in the speech. Our study is structured by time concepts researched in philosophy, psychology, linguistics, sociology, physiology, 
biology, astronomy. It gives us the opportunity to consider the time image as an innate one in the consciousness. We propose to use so called language time for describing it. We also believe the time image as a nationally and culturally determined one in the language consciousness. We put in the term speech time for outlining it. The relation between the innate image of time and the national image of time in the language consciousness could be the ground for future analysis, as well as the language and speech time examination in chronopsycholinguistics.

\section{Acknowledgments}

This paper was financially supported by the Russian Foundation for Basic Research, grant No. 20-012-22046.

\section{References}

1. A.V. Bondarko, Principles of functional grammar and questions of Aspectology / ed. by V. N. Yartsev /, 2nd ed., Moscow, Russia (2001)

2. A. A. Ershov, Time, Saint Petersburg, Russia (2000)

3. V. A. Ilyina, D. V. Dragaitsev, What is chronopsycholinguistica?, Scientific notes of the National society of applied linguistics, 3(27), 114-119, Moscow, Russia (2019)

4. B. I. Tsukanov, Time in the human psyche, Odessa, Ukraine (2000)

5. D. G. El'kin, Perception of time, Moscow, Russia (1962)

6. I.V. Vashunina, V.V. Dronov., V.A. Ilyina, D.V. Mahovikov, A.A. Nistratov, S.L. Nistratova, E. K. Oshchepkova, E.F. Tarasov, Bazovye cennosti nositelej russkoj kul'tury, Moscow, Russia (2019)

7. E.F. Tarasov, Obshchechelovecheskie cennosti: proekt issledovaniya, Voprosy psiholingvistiki, 1 (15), 9-17, Moscow, Russia (2012)

8. T. I. Lomtev, Predlozhenie i ego grammaticheskie kategorii, Moscow, Russia (1972)

9. T.A. Nestik, Social'naya psihologiya vremeni, Moscow, Russia (2014)

10. E.A. Referovskaya, Aspektual'nye znacheniya francuzskogo glagola, Teoriya grammaticheskogo znacheniya i aspektologicheskie issledovaniya, 91-109, Saint Petersburg, Russia (1984)

11. V.A. Ilyina, Odinochestvo v yazykovom soznanii nositelej russkoj i anglijskoj kul'tur, Moscow, Russia (2011) 